\title{
Erratum
}

\section{A HIGH SENSITIVITY AND WIDE DYNAMIC RANGE ZERO-IF RF RECEIVER FOR COGNITIVE RADIO APPLICATION ${ }^{1}$}

\author{
Liu Jing Zhu Xiaowei Zhang Xiaodong You Changjiang \\ (State Key Laboratory of Millimeter Waves, Southeast University, Nanjing 210096, China)
}

DOI $10.1007 / \mathrm{s} 11767-011-1004-\mathrm{z}$

The original online version of this article (Journal of Electronics (China), Vol. 27, No.5, September 2010, pp.696-700; DOI: 10.1007/s11767-011-0499-7) unfortunately contains mistakes in the right part of headers on Pages 698 and 700. The issue number and published month are wrong. The correct form should be No.5 September 2010. 